\title{
Development and validation of a risk prediction model for radiotherapy-related esophageal fistula in esophageal cancer
}

\author{
Yiyue $\mathrm{Xu}^{1,2}$, Linlin Wang ${ }^{2^{*}} \mathbb{D}$, Bo He $\mathrm{H}^{1,3}$, Wanlong $\mathrm{Li}^{2}$, Qiang Wen ${ }^{3}$, Shijiang Wang ${ }^{2}$, Xindong Sun ${ }^{2}$, Xue Meng ${ }^{2^{*}}$ and \\ Jinming $Y u^{2}$
}

\begin{abstract}
Objectives: We aimed to identify the risk factors and provide a nomogram for the prediction of radiotherapy-related esophageal fistula in patients with esophageal cancer (EC) using a case-control study.

Patients and methods: Patients with esophageal fistula who received radiotherapy or chemoradiotherapy between 2003 and 2017 were retrospectively collected in two institutions. In the training cohort (TC), clinical, pathologic, and serum data of 136 patients (cases) who developed esophageal fistula during or after radiotherapy were enrolled and compared with 272 controls (1:2 matched with the diagnosis time of EC, sex, marriage, and race). After the univariable and multivariable logistic regression analyses, the independent risk factors were identified and incorporated into a nomogram. Then the nomogram for the risk prediction was externally validated in the validation cohort (VC; 47 cases and 94 controls) using bootstrap resampling.
\end{abstract}

Results: Multivariable analyses demonstrated that ECOG PS, BMI, T4, N2/3 and re-radiotherapy were independent factors for esophageal fistula. Then a nomogram was constructed with the C-index of 0.805 ( $95 \% \mathrm{Cl}, 0.762-0.848)$ for predicting the risk of developing esophageal fistula in EC patients receiving radiotherapy. Importantly, the C-index maintained 0.764 ( $95 \% \mathrm{Cl}, 0.683-0.845)$ after the external validation.

Conclusions: We created and externally validated the first risk nomogram of esophageal fistula associated with radiotherapy. This will aid individual risk stratification of patients with EC developing esophageal fistula.

Keywords: Esophageal cancer, Radiotherapy, Esophageal fistula, Risk factors, Nomogram

\section{Introduction}

Esophageal cancer is a common malignancy of the digestive tract, ranking the 8th in global malignant tumors [1]. The incidence of EC in China is higher than the global average and is the fourth leading cause of cancer-related death [2]. Radiotherapy is one of the main therapeutic strategies for the control of EC disease, which includes the neoadjuvant/adjuvant therapy, radical radiotherapy and palliative radiotherapy [3]. Nearly one half of the EC patients will receive radiotherapy during their disease course

\footnotetext{
* Correspondence: wanglinlinatjn@163.com; mengxue5409@126.com ${ }^{2}$ Department of Radiation Oncology, Shandong Cancer Hospital and Institute, Shandong First Medical University and Shandong Academy of Medical Sciences, No.440, Ji Yan Road, Jinan, Shandong 250012, People's Republic of China

Full list of author information is available at the end of the article
}

[4-6]. However, the adverse events unavoidably occurred, and sometimes threatened the patient life.

Esophageal fistula is one of the serious complications related with the radiotherapy, and $4.3-24 \%$ patients were reported to develop esophageal fistula after the chemoradiotherapy [4, 7-13]. Due to the related infection, massive hemorrhage or unhealed abscess [14-17], the prognosis of patients with esophageal fistula was extremely poor; with the median survival of only two or 3 months [17-19]. Therefore, early prediction of esophageal fistula is very important for reducing the risk of death and improving the patient prognosis.

Some studies have shown that low serum cholesterol level, T4 stage, ulcerative type, and re-radiotherapy were related to the occurrence of esophageal fistula [12, 15-17, $19,20]$. However, the sample size is always relatively small,

(c) The Author(s). 2019 Open Access This article is distributed under the terms of the Creative Commons Attribution 4.0 International License (http://creativecommons.org/licenses/by/4.0/), which permits unrestricted use, distribution, and 
and often limitedly enrolled patients with advanced squamous cell carcinoma [16]. Besides, some patients with the esophageal fistula also received the treatment of surgery which may also contribute to the fistula [21]. Thus, the assessment of risk from radiotherapy may be influenced by the confound factors. More importantly, no risk model has been established for quantitatively predicting the occurrence of esophageal fistula.

Therefore, we attempted to retrospectively analyze the risk factors of esophageal fistula in EC patients who received radiotherapy but not surgery, and developed a nomogram to predict the occurrence of radiotherapyrelated esophageal fistula.

\section{Materials and methods Patients}

This retrospective study was approved by the Institutional Review Board of Shandong Cancer Hospital and Shandong Provincial Hospital. For this retrospective study, formal written informed consent from all patients was not required, and all data were kept confidential. The patient records of all EC patients treated with radiotherapy or chemoradiotherapy between 2003 and 2017 were reviewed and the patients who developed esophageal fistula were further identified. The inclusion criteria were 1) diagnosed as EC by pathological biopsy; 2) received radical radiotherapy/chemoradiation, palliative radiotherapy/chemoradiation, or a second course of radiotherapy to EC; 3) diagnosed as esophageal fistula by endoscopy, CT or $\mathrm{X}$-ray with meglumine diatrizoate. Exclusion criteria were 1) underwent esophageal surgery; 2) other causes contributed to the esophageal fistula, such as medical injure or trauma; 3 ) the fistula was developed before treatment or assessed by the disease progression; 4) concomitant with another carcinoma. Eligible patients who developed esophageal fistula were included into the case group. Controls were matched to cases with 1:2 by the diagnosis time of EC, sex, marriage, and race. One hundred thirty-six patients with esophageal fistula and 272 controls in Shandong Cancer Hospital were used as training cohort (TC); 47 cases and 94 controls from Shandong Provincial Hospital were separately assigned as the independent external validation cohort (VC).

\section{Data collection}

Data were collected using a standardized questionnaire. Information collected included general (age, ECOG PS, BMI, history of smoking and history of diabetes), diagnostic (T4, N2/3, longitudinal length of lesions and general type), treatment-related (re-radiotherapy, radiotherapy dose and chemotherapy), and hematological data (serum cholesterol and albumin) which is reported in Additional file 1 . All the data were 1 month before radiotherapy.

\section{Variables definition}

ECOG PS is defined as Eastern Cooperative Oncology Group performance status. BMI (Body Mass Index) is calculated using the international standard method: weight squared/height. Smoking is defined as smoking at least one cigarette a day for at least 1 year. TNM stage is in accordance with the UICC-TNM classification 7th edition. Chemotherapy is defined as receiving chemotherapy before radiotherapy or concurrent chemoradiotherapy.

\section{Statistical analysis}

The association of various factors with the risk of esophageal fistula were assessed by conditional logistic regression. $95 \%$ confidence intervals $(95 \% \mathrm{CI})$ and $P$ value are calculated for overall effect for factors in the study. Based on a $P$ value $<0.1$ in univariate analyses, factors were selected into the multivariate analysis. The nomogram for the prediction of probability of radiotherapy-related esophageal fistula were established with the results of multivariate analysis.

The predictive ability of the nomogram was assessed by concordance index (C-index). Calibration curves were analyzed by plotting the nomogram predicted and the actual probability of the occurrence of esophageal fistula. During the external validation, the total points of each patient in the validation cohort were calculated according to the established nomogram, then logistic regression in this cohort was performed using the total points as a factor, and finally, the C-index and calibration curve were derived based on the regression analysis.

Statistics analysis were performed using SPSS 24.0 version and $\mathrm{R}$ version 3.5 for Windows.

\section{Results}

\section{Patient characteristics}

During the study period, 18,169 EC patients were treated with radiotherapy in these two institutions. Esophageal fistula occurred in 541 patients. After excluding patients who developed fistula due to other reasons, 183(1.01\%) EC patients developed esophageal fistula during or after radiotherapy. Controls who received radiotherapy/chemoradiotherapy but no surgery were matched to cases. All eligible patients were divided into TC and VC by different treatment institutions (Fig. 1).

Among the 183 EC patients, 88 were diagnosed as fistula by CT; 84 were diagnosed by esophagogram; 11 were diagnosed by endoscopic. Perforation occurred during radiotherapy in 38 patients, while 145 patients developed fistula after radiotherapy. All patients who developed esophageal fistula during radiotherapy discontinued radiotherapy. The median intervals between the termination of radiotherapy and occurrence of fistula were 5 months. In 145 patients who finished the radiotherapy, a majority of patients (97) accepted a dose 


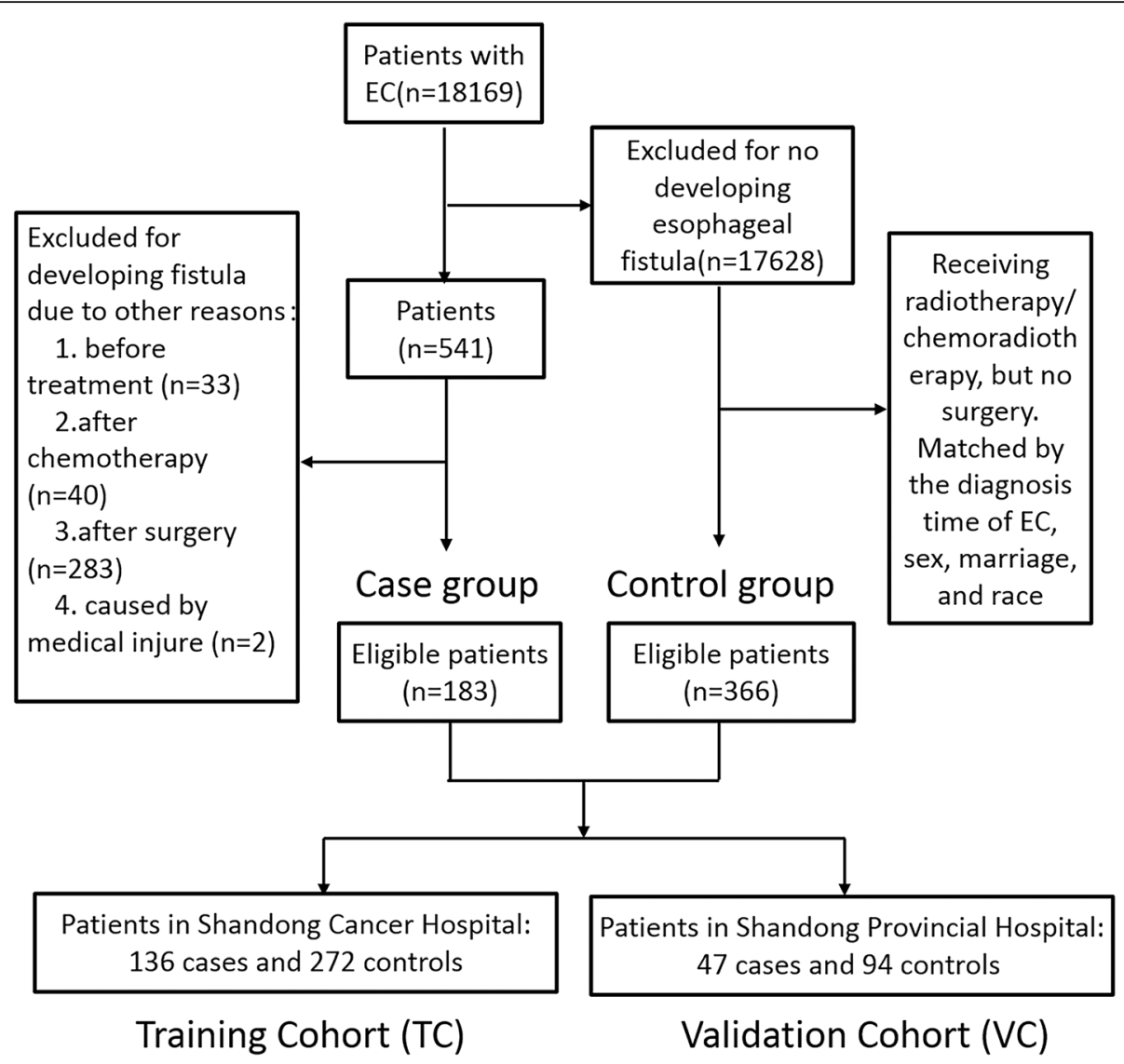

Fig. 1 Flow chart for patient selection

$\geq 60$ Gy; 36 patients accepted $\geq 50<60$ Gy; and only 12 patients accepted $<50 \mathrm{~Gy}$. In the treatment methods of esophageal fistula, 39 patients were treated conservatively with parenteral nutrition, 61 with esophageal stent, 41 with nutrient canal, 17 with gastrostomy, 2 with radical resection (Table 1).

\section{Univariate analysis and multivariate analysis of risk factors associated with esophageal cancer}

In the $\mathrm{TC}$, conditional logistic regression was performed for the determination of the potential risk factors of esophageal fistula. On the univariable logistical regression analysis, a significant difference can be detected between the cases and controls in terms of ECOG PS $\geq$ 3 , BMI, T4, N2/3, the longitudinal length of lesions, reradiotherapy, Taxol chemotherapy and serum cholesterol ( $p$ all $<0.1$ ). No significant differences were observed regarding smoking history, diabetes history, and other factors.

On multivariate analysis, ECOG $\mathrm{PS} \leq 2$ and $\mathrm{BMI} \geq$ $18.5 \mathrm{~kg} / \mathrm{m}^{2}$ were the protective factors for the occurrence of esophageal fistula. On the contrary, T4, N2/3 and re-radiotherapy were the independent risk factors for EC patients (Table 2).

\section{Prognostic nomogram and the validation of predictive accuracy}

Based on these independent factors, a nomogram was constructed for predicting the probability of the occurrence of esophageal fistula in EC patients receiving radiotherapy. The point of each factor can be determined according to the intersection of the vertical line drawn from the variable to the point axis. Then, the total risk score was calculated by adding all the variable points; and the probability of the occurrence of esophageal fistula can be directly read on the total point axis. The C- index of this risk nomogram was 0.805 , (95\% CI: $0.762-0.848)$. The calibration curves showed a good agreement between the risk estimation by the nomogram and actual observation (Fig. 2).

The nomogram's performance was then assessed in the VC. A C-index of 0.764 (95\% CI: 0.683-0.845) was observed. The calibration curves also indicated that the predicted probabilities by the nomogram were good match with the clinical confirmation (Fig. 2).

\section{Discussion}

This study comprehensively evaluated the risk factors in the occurrence of radiotherapy-related esophageal fistula 
Table 1 Characteristics of patients with radiotherapy-related esophageal fistula

\begin{tabular}{|c|c|c|c|c|}
\hline \multirow[t]{2}{*}{ Characteristics } & \multicolumn{2}{|c|}{$\begin{array}{l}\text { Training } \\
\text { cohort }\end{array}$} & \multicolumn{2}{|c|}{$\begin{array}{l}\text { Validation } \\
\text { cohort }\end{array}$} \\
\hline & $\mathrm{N}$ & $\%$ & $\mathrm{~N}$ & $\%$ \\
\hline Age (years), mean \pm SD & \multicolumn{2}{|c|}{$61.8 \pm 8.9$} & \multicolumn{2}{|c|}{$60.2 \pm 10.7$} \\
\hline \multicolumn{5}{|l|}{ ECOG PS } \\
\hline$\leq 2$ & 94 & 69.1 & 32 & 68.1 \\
\hline$\geq 3$ & 42 & 30.9 & 15 & 31.9 \\
\hline \multicolumn{5}{|l|}{ T stage } \\
\hline $\mathrm{T} 1-3$ & 85 & 62.5 & 34 & 72.3 \\
\hline T4 & 51 & 37.5 & 13 & 27.7 \\
\hline \multicolumn{5}{|l|}{$N$ stage } \\
\hline No-1 & 69 & 50.7 & 20 & 42.6 \\
\hline N2-3 & 67 & 49.3 & 27 & 57.4 \\
\hline \multicolumn{5}{|l|}{ Stage } \\
\hline । & 0 & 0 & 0 & 0 \\
\hline$\|$ & 14 & 10.3 & 5 & 10.6 \\
\hline III & 91 & 66.9 & 29 & 61.7 \\
\hline IV & 31 & 22.8 & 13 & 27.7 \\
\hline \multicolumn{5}{|l|}{ Chemotherapy } \\
\hline Yes & 98 & 72.1 & 33 & 70.2 \\
\hline No & 38 & 27.9 & 14 & 29.8 \\
\hline \multicolumn{5}{|l|}{ Re-radiotherapy } \\
\hline Yes & 25 & 18.4 & 6 & 12.8 \\
\hline No & 111 & 81.6 & 41 & 87.2 \\
\hline \multicolumn{5}{|l|}{ Single dose of radiation (Gy) } \\
\hline$\leq 2$ & 129 & 4.9 & 7 & 0.0 \\
\hline$>2$ & 7 & 5.1 & 0 & 0 \\
\hline \multicolumn{5}{|l|}{ Total dose (patients who finished the radiotherapy) } \\
\hline$\geq 60 G y$ & 58 & 57.4 & 39 & 88.6 \\
\hline$\geq 50<60 \mathrm{~Gy}$ & 34 & 33.7 & 2 & 4.6 \\
\hline$<50 G y$ & 9 & 8.9 & 3 & 6.8 \\
\hline \multicolumn{5}{|l|}{ Diagnostic tool } \\
\hline CT & 76 & 55.9 & 12 & 25.5 \\
\hline Esophagogram & 59 & 43.4 & 25 & 53.2 \\
\hline Endoscopic & 1 & 0.7 & 10 & 21.3 \\
\hline \multicolumn{5}{|l|}{ Occurrence time } \\
\hline During radiotherapy & 35 & 25.7 & 3 & 6.4 \\
\hline After radiotherapy & 101 & 74.3 & 44 & 93.6 \\
\hline $\begin{array}{l}\text { Median time between the end of radiotherapy } \\
\text { and fistula (month) }\end{array}$ & 4.5 & & 5.5 & \\
\hline \multicolumn{5}{|l|}{ Fistula type } \\
\hline Esophageal-respiratory & 67 & 49.3 & 40 & 85.1 \\
\hline Esophageal-mediastinum & 66 & 48.5 & 4 & 8.5 \\
\hline Esophagopleural fistula & 2 & 1.5 & 1 & 2.1 \\
\hline Both esophageal-respiratory and & 1 & 0.7 & 2 & 4.3 \\
\hline
\end{tabular}

Table 1 Characteristics of patients with radiotherapy-related esophageal fistula (Continued)

\begin{tabular}{|c|c|c|c|c|}
\hline \multirow[t]{2}{*}{ Characteristics } & \multicolumn{2}{|c|}{$\begin{array}{l}\text { Training } \\
\text { cohort }\end{array}$} & \multicolumn{2}{|c|}{$\begin{array}{l}\text { Validation } \\
\text { cohort }\end{array}$} \\
\hline & $\mathrm{N}$ & $\%$ & $\mathrm{~N}$ & $\%$ \\
\hline \multicolumn{5}{|c|}{ esophageal-mediastinum fistula. } \\
\hline \multicolumn{5}{|l|}{ Therapy } \\
\hline Conservative treatment & 31 & 22.8 & 8 & 17.0 \\
\hline Esophageal stent & 31 & 22.8 & 30 & 63.8 \\
\hline Nutrient canal & 36 & 26.5 & 5 & 10.6 \\
\hline Gastrostomy & 15 & 11.0 & 2 & 4.3 \\
\hline Radical resection & 2 & 1.5 & 0 & 0 \\
\hline Others & 21 & 15.4 & 2 & 4.3 \\
\hline
\end{tabular}

in patients with EC and developed a reliable nomogram. Of the currently available prediction tools, a nomogram is a graphic representation of the solution of an equation and has a good discrimination characteristic in predicting outcomes which is easy to use [22]. To our best knowledge, the established nomogram is the first model for predicting esophageal fistula probability and externally validated.

In the present study, patients with T4 stage had higher probability to develop esophageal fistula, due to the deeper tumor invasion depth. When tumor declined after radiotherapy, normal tissue repaired relatively slowly, which was easy to develop fistula [20, 23]. Consistent with the findings of conformal radiotherapy by Chen Haiyan [19], we found that the proportion of patients with T4 disease in the case group was much higher than that in the control group (35.0\% vs. $16.9 \%$ ). Besides, N2/3 was another independent risk factor. The increase of $\mathrm{N}$ staging lead to the enlargement of the target area according to the NCCN Guidelines which are much more likely to increase the risk of developing esophageal fistula.

Our study also suggested re-radiotherapy would increase the risk of radiation-related esophageal fistula; it may demonstrate that patients with $\mathrm{T} 4$ or N2/3 should be more cautious in the choice of re-radiotherapy to avoid esophageal perforation [24]. The risk score can help to stratify the patients with high risk of radiation-related esophageal fistula and provide alternative therapeutic strategy other than re-radiotherapy for local recurrence, such as surgery and chemotherapy.

Tsushima [16] reported the effect of BMI on the occurrence of esophageal fistula, but only compared the difference between $\mathrm{BMI} \leq 20$ and $\mathrm{BMI}>20$. In this study, BMI was divided to four grades according the international standard, so that the differences between different BMI could be compared more accurately. BMI was found to be a protective factor for the esophageal fistula; less BMI was associated with the more elevated risk of esophageal fistula. 
Table 2 Univariate and multivariate analysis of risk factors in training cohort

\begin{tabular}{|c|c|c|c|c|}
\hline \multirow[t]{2}{*}{ Factors } & \multicolumn{2}{|c|}{ Univariate } & \multicolumn{2}{|c|}{ Multivariate } \\
\hline & $P$ & OR $(95.0 \% \mathrm{Cl})$ & $P$ & OR $(95.0 \% \mathrm{Cl})$ \\
\hline \multicolumn{5}{|l|}{ Age (years) } \\
\hline$<60$ & 0.944 & $1.015(0.673-1.529)$ & & \\
\hline \multicolumn{5}{|l|}{$\geq 60$} \\
\hline \multicolumn{5}{|l|}{ ECOG PS } \\
\hline$\leq 2$ & $<0.001$ & $7.922(3.828-16.396)$ & $<0.001$ & $5.165(2.180-12.242)$ \\
\hline \multicolumn{5}{|l|}{$\geq 3$} \\
\hline \multicolumn{5}{|l|}{ BMI $\left(\mathrm{kg} / \mathrm{m}^{2}\right)$} \\
\hline$<18.5$ & $<0.001$ & 1.00(reference) & 0.001 & 1.00(reference) \\
\hline $18.5-23.9$ & & $0.283(0.138-0.583)$ & & $0.371(0.164-0.837)$ \\
\hline $24-27.9$ & & $0.154(0.066-0.360)$ & & $0.176(0.065-0.480)$ \\
\hline$\geq 28$ & & $0.038(0.010-0.150)$ & & $0.059(0.012-0.287)$ \\
\hline \multicolumn{5}{|l|}{ History of Smoking } \\
\hline No & 0.137 & $1.381(0.903-2.112)$ & & \\
\hline \multicolumn{5}{|l|}{ Yes } \\
\hline \multicolumn{5}{|l|}{ History of diabetes } \\
\hline No & 0.638 & $0.843(0.414-1.716)$ & & \\
\hline \multicolumn{5}{|l|}{ Yes } \\
\hline \multicolumn{5}{|l|}{ T stage } \\
\hline $\mathrm{T} 1-3$ & $<0.001$ & $2.853(1.763-4.617)$ & 0.018 & $2.123(1.137-3.965)$ \\
\hline \multicolumn{5}{|l|}{ T4 } \\
\hline \multicolumn{5}{|l|}{ N stage } \\
\hline No-1 & $<0.001$ & $2.355(1.527-3.629)$ & 0.003 & $2.489(1.377-4.499)$ \\
\hline \multicolumn{5}{|l|}{ N2-3 } \\
\hline Longitudinal length of lesions & 0.020 & $1.096(1.015-1.185)$ & 0.246 & $1.064(0.958-1.181)$ \\
\hline \multicolumn{5}{|l|}{ General type } \\
\hline Medullary type & 0.409 & 1.00(reference) & & \\
\hline Mushroom type & & $1.458(0.810-2.627)$ & & \\
\hline Ulcerative type & & $1.607(0.936-2.760)$ & & \\
\hline Constrictive type & & $0.992(0.448-2.196)$ & & \\
\hline Cavity type & & $0.941(0.278-3.182)$ & & \\
\hline \multicolumn{5}{|l|}{ Re-radiotherapy } \\
\hline No & $<0.001$ & $6.262(2.682-14.620)$ & $<0.001$ & $10.392(3.491-30.938)$ \\
\hline \multicolumn{5}{|l|}{ Yes } \\
\hline \multicolumn{5}{|l|}{ Single dose of radiation (Gy) } \\
\hline$\leq 2$ & 1.000 & $1.000(0.404-2.478)$ & & \\
\hline \multicolumn{5}{|l|}{$>2$} \\
\hline \multicolumn{5}{|l|}{ Chemotherapy } \\
\hline No & 0.500 & $1.166(0.746-1.821)$ & & \\
\hline \multicolumn{5}{|l|}{ Yes } \\
\hline \multicolumn{5}{|l|}{ Chemotherapy } \\
\hline 0 line & 0.307 & 1.00(reference) & & \\
\hline 1 line & & $1.072(0.678-1.695)$ & & - \\
\hline 2 line & & $1.990(0.841-4.710)$ & & - \\
\hline
\end{tabular}


Table 2 Univariate and multivariate analysis of risk factors in training cohort (Continued)

\begin{tabular}{|c|c|c|c|c|}
\hline \multirow[t]{2}{*}{ Factors } & \multicolumn{2}{|c|}{ Univariate } & \multicolumn{2}{|c|}{ Multivariate } \\
\hline & $P$ & OR $(95.0 \% \mathrm{Cl})$ & $P$ & OR $(95.0 \% \mathrm{Cl})$ \\
\hline 3 line and more & & $2.367(0.496-11.306)$ & & \\
\hline \multicolumn{5}{|l|}{ Taxol chemotherapy } \\
\hline No & 0.031 & $1.592(1.043-2.428)$ & 0.128 & $1.524(0.886-2.622)$ \\
\hline \multicolumn{5}{|l|}{ Yes } \\
\hline \multicolumn{5}{|c|}{ Serum cholesterol (mmol/l) } \\
\hline$<4.40$ & 0.029 & $0.819(0.656-1.024)$ & 0.056 & $0.557(0.305-1.016)$ \\
\hline \multicolumn{5}{|l|}{$\geq 4.40$} \\
\hline \multicolumn{5}{|l|}{ Serum albumin (g/dl) } \\
\hline$<3.5$ & 0.495 & $0.936(0.887-0.988)$ & & \\
\hline$\geq 3.5$ & & & & \\
\hline
\end{tabular}

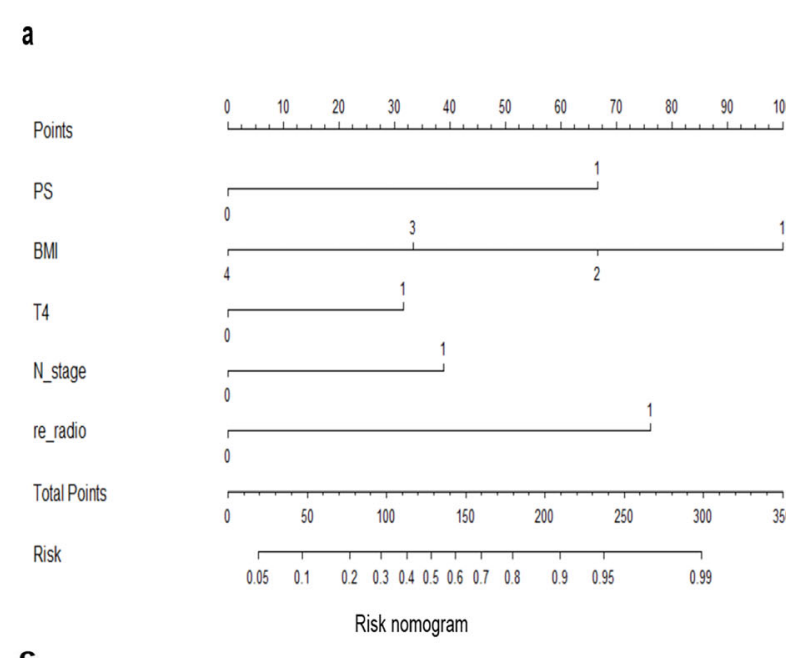

\section{b}
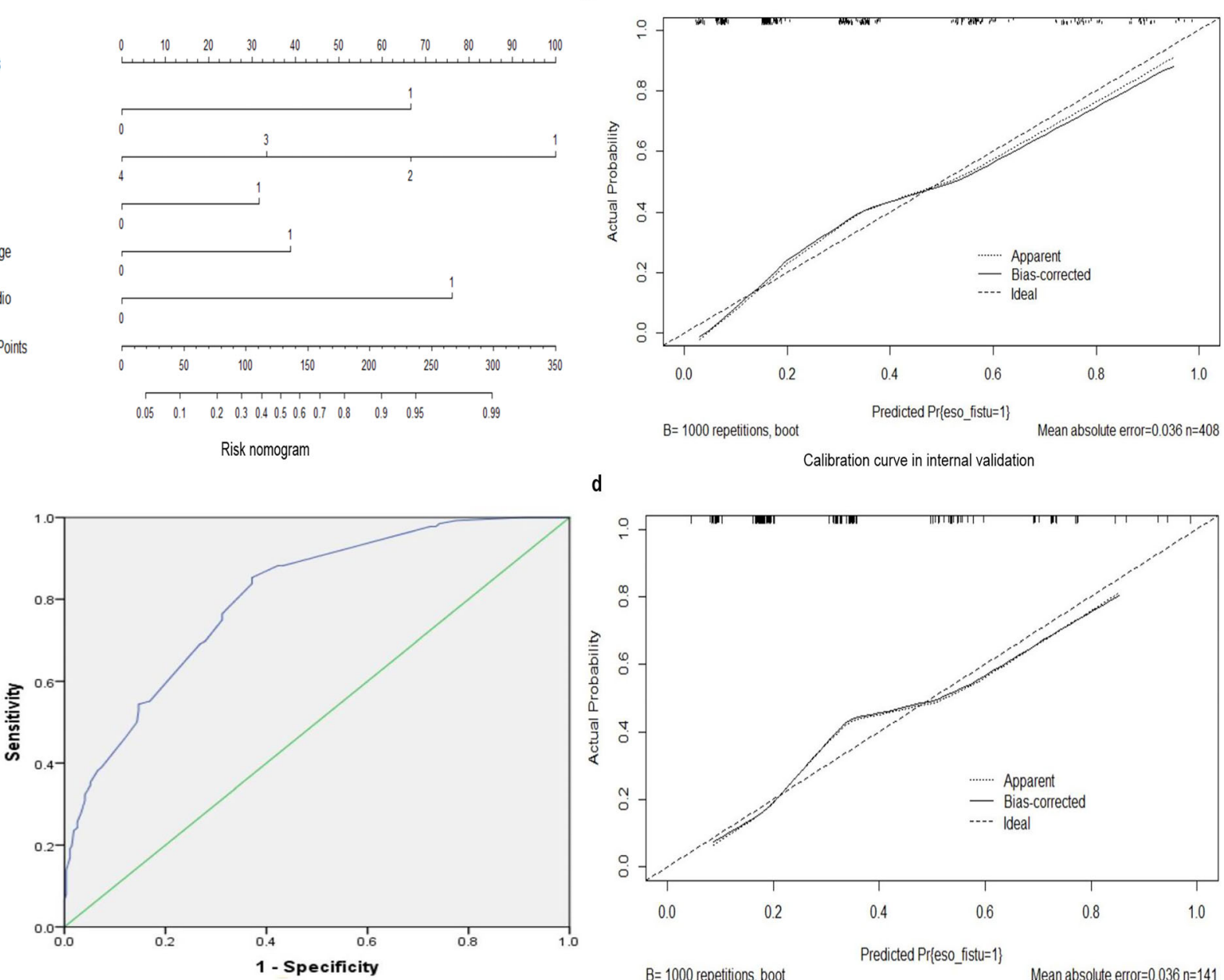

ROC curve in the internal validation sample

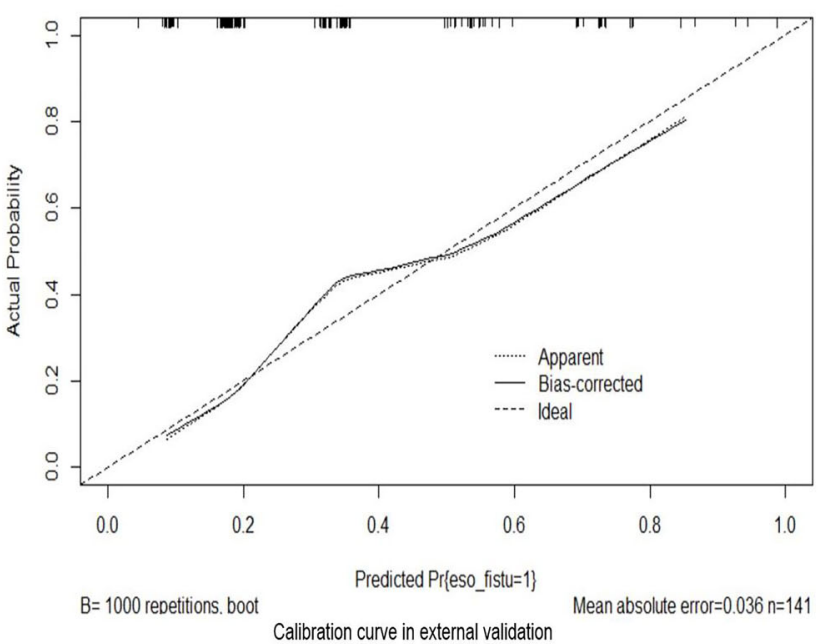

Fig. 2 a Nomogram for individualized prediction of radiotherapy-related esophageal fistula in patients with esophageal cancer. PS 0: ECOG PS $\leq$ 2; 1: ECOG PS $\geq 3$. BMI 1: $<18.5 \mathrm{~kg} / \mathrm{m}^{2} ; 2: 18.5-23.9 \mathrm{~kg} / \mathrm{m}^{2} ; 3: 24-27.9 \mathrm{~kg} / \mathrm{m}^{2} ; 4: \geq 28 \mathrm{~kg} / \mathrm{m}^{2}$. T4 0: T1-3 stage; 1: T4 stage. N_stage 0: N0-1 stage; 1 : N2-3 stage. re_radio 0: no re-radiotherapy; 1: re-radiotherapy. $\mathbf{b}$ Calibration curve in internal validation. c Receiver under the operator characteristic $(\mathrm{ROC})$ curve for the test accuracy of the final risk score in the internal validation sample (C-index $=0.805,95 \% \mathrm{Cl} 0.762$ to 0.848$)$. $\mathbf{d}$ Calibration curve in external validation 
Moreover, the patients with high ECOG PS also was the independent factor for the developing of esophageal fistula. High ECOG PS and low BMI were related to the poor nutritional [25] and immune status [26], which may cause the impaired capability of repairing in tumor tissues.

Although the level of serum cholesterol was found to be related with the occurrence of esophageal fistula, patients with less than $170 \mathrm{mg} / \mathrm{dl}$ were 14.7 times more likely to develop arterio-esophageal fistula after chemoradiotherapy than those with high cholesterol; only 48 samples were included in the study [15]. In our present study, the patients in the esophageal fistula group also had lower total cholesterol level in univariate logistic regression analysis, but lose the statistical significance in multivariate, demonstrating the level of serum cholesterol may be influenced by other risk factors and was a confounding factor.

Using the nomogram, patients with high scores $(>180$ points) are $80 \%$ more likely to develop esophageal fistula. Clinicians should ensure that esophagogram is examined once a week during radiotherapy and pay more attention on these patients during follow-up. Timely treatment should be given to patients who cough or choke drinking water. Studies have shown that esophageal bypass operation before definitive chemoradiotherapy can reduce the incidence of esophageal fistula [27].

This study has several limitations. As a case control study, there may be selection bias. We use a third party to collect data in both case and control group, to minimize observational bias. In addition, this study was a retrospective study in which some patients were enrolled without endoscopic ultrasonography, so the parameters of esophageal stenosis can't be assessed. Because the study population was all Han Chinese, the results may be verified in the western patients and the prospective clinical trials were urgently needed in the future.

\section{Conclusion}

Combing the risk factors, a nomogram was constructed and externally validated for the prediction of esophageal fistula associated with radiotherapy. This tool might be helpful for individualized stratifying the patients with different risk of esophageal fistula and lead to a rational therapeutic choice in patients with EC.

\section{Supplementary information}

Supplementary information accompanies this paper at https://doi.org/10. 1186/s13014-019-1385-y.

Additional file 1. Characteristics of patients.

\section{Abbreviations}

BMI: Body mass index; Cl: Confidence interval; C-index: Concordance index; EC: Esophageal cancer; ECOG PS: Eastern Cooperative Oncology Group performance status; TC: Training cohort; TNM: Tumor-node-metastasis; VC: Validation cohort

\section{Acknowledgements}

The authors thank all patients who participated in the study.

\section{Authors' contributions}

LW, XM and JY made contributions to the conception and design of the study. YX, BH and QW collected the clinical data. $\mathrm{YX}$ and $\mathrm{BH}$ performed the statistical analysis and drafted the manuscript. LW revised the article critically for important intellectual content. WL, SW, and XS were involved in study implementation. All authors read and approved the final manuscript.

\section{Funding}

This study was supported by the Project of Postdoctoral Innovation of Shandong Province (Grant No. 201501010 and 201601006), the Project of Postdoctoral Science Foundation of China (Grant No. 2016M590640), Key Research and Development Program of China (Grant No. 2018YFC1313201) and Key Research and Development Program of Shandong Province (Grant No. 2016CYJS01A03).

\section{Availability of data and materials}

The datasets used and/or analyzed during the study are available from the corresponding author on reasonable request.

\section{Ethics approval and consent to participate}

This study was approved by the Institutional Review Board of Shandong Cancer Hospital (no SDTHEC201801007). For this retrospective study, formal written informed consent from all patients was not required, and all data were kept confidential.

Consent for publication

Not applicable.

\section{Competing interests}

The authors declare that they have no competing interests.

\section{Author details}

${ }^{1}$ School of Medicine, Shandong University, Jinan, China. ${ }^{2}$ Department of Radiation Oncology, Shandong Cancer Hospital and Institute, Shandong First Medical University and Shandong Academy of Medical Sciences, No.440, Ji Yan Road, Jinan, Shandong 250012, People's Republic of China. ${ }^{3}$ Provincial Hospital Affiliated to Shandong University, Jinan, China.

Received: 22 June 2019 Accepted: 25 September 2019

Published online: 22 October 2019

\section{References}

1. Ferlay J, Soerjomataram I, Dikshit R, Eser S, Mathers C, Rebelo M, et al. Cancer incidence and mortality worldwide: sources, methods and major patterns in GLOBOCAN 2012. Int J Cancer. 2015;136(5):E359-86.

2. Chen W, Zheng R, Baade PD, Zhang S, Zeng H, Bray F, et al. Cancer statistics in China, 2015. CA Cancer J Clin. 2016;66(2):115-32.

3. Muro K, Lordick F, Tsushima T, Pentheroudakis G, Baba E, Lu Z, et al. PanAsian adapted ESMO Clinical Practice Guidelines for the management of patients with metastatic oesophageal cancer: a JSMO-ESMO initiative endorsed by CSCO, KSMO, MOS, SSO and TOS. J Ann Oncol. 2019;1(30):3443.

4. Shinoda M, Ando N, Kato K, Ishikura S, Kato H, Tsubosa Y, et al. Randomized study of low-dose versus standard-dose chemoradiotherapy for unresectable esophageal squamous cell carcinoma (JCOG0303). Cancer Sci. 2015;106(4):407-12.

5. van Hagen P, Hulshof MC, van Lanschot JJ, Steyerberg EW, van Berge Henegouwen MI, Wijnhoven BP, et al. Preoperative chemoradiotherapy for esophageal or junctional cancer. N Engl J Med. 2012;366(22):2074-84.

6. Shapiro J, van Lanschot JJB, Hulshof M, van Hagen P, van Berge Henegouwen MI, Wijnhoven BPL, et al. Neoadjuvant chemoradiotherapy plus surgery versus surgery alone for oesophageal or junctional cancer (CROSS): long-term results of a randomised controlled trial. Lancet Oncol. 2015;16(9):1090-8

7. Hihara J, Hamai Y, Emi M, Murakami Y, Kenjo M, Nagata Y, et al. Role of definitive chemoradiotherapy using docetaxel and 5-fluorouracil in patients with unresectable locally advanced esophageal squamous cell carcinoma: a phase II study. Dis. Esophagus. 2016;29(8):1115-20. 
8. Oh D, Noh JM, Nam H, Lee H, Kim TG, Ahn YC. High-dose radiation therapy alone by moderate hypofractionation for patients with thoracic esophageal squamous cell carcinoma. Medicine. 2016;95(33):e4591.

9. Zhou ZG, Zhen CJ, Bai WW, Zhang P, Qiao XY, Liang JL, et al. Salvage radiotherapy in patients with local recurrent esophageal cancer after radical radiochemotherapy. Radiat Oncol. 2015;10:54.

10. Sun $X$, Han S, Gu F, Lin G, Wang Z, Wang Y, et al. A retrospective comparison of Taxane and fluorouracil-based Chemoradiotherapy in patients with inoperable esophageal squamous cell carcinoma. J Cancer. 2016;7(9):1066-73.

11. Chen Y, Lu Y, Wang Y, Yang H, Xia Y, Chen M, et al. Comparison of salvage chemoradiation versus salvage surgery for recurrent esophageal squamous cell carcinoma after definitive radiochemotherapy or radiotherapy alone. Dis Esophagus. 2014;27(2):134-40.

12. Kawakami T, Tsushima T, Omae K, Ogawa H, Shirasu H, Kito Y, et al. Risk factors for esophageal fistula in thoracic esophageal squamous cell carcinoma invading adjacent organs treated with definitive chemoradiotherapy: a monocentric case-control study. BMC Cancer. 2018; 18(1):573.

13. Wang Q, Li T, Lang J, Wang J, Wang J, Liu H, et al. A retrospective study of californium-252 neutron brachytherapy combined with EBRT versus 3D-CRT in the treatment of esophageal squamous cell cancer. Radiat Oncol. 2015;10:212.

14. Tu L, Sun L, Xu Y, Wang Y, Zhou L, Liu Y, et al. Paclitaxel and cisplatin combined with intensity-modulated radiotherapy for upper esophageal carcinoma. Radiat Oncol. 2013;8:75.

15. Taniguchi H, Yamazaki K, Boku N, Funakoshi T, Hamauchi S, Tsushima T, et al. Risk factors and clinical courses of chemoradiation-related arterioesophageal fistula in esophageal cancer patients with clinical invasion of the aorta. Int J Clin Oncol. 2011;16(4):359-65.

16. Tsushima T, Mizusawa J, Sudo K, Honma Y, Kato K, Igaki H, et al. Risk factors for esophageal fistula associated with Chemoradiotherapy for locally advanced Unresectable esophageal Cancer: a supplementary analysis of JCOG0303. Medicine. 2016;95(20):e3699.

17. Zhang Y, Li Z, Zhang W, Chen W, Song Y. Risk factors for esophageal fistula in patients with locally advanced esophageal carcinoma receiving chemoradiotherapy. OncoTargets Ther. 2018;11:2311-7.

18. Rodriguez AN, Diaz-Jimenez JP. Malignant respiratory-digestive fistulas. Curr Opin Pulm Med. 2010;16(4):329-33.

19. Chen HY, Ma XM, Ye M, Hou YL, Xie HY, Bai YR. Esophageal perforation during or after conformal radiotherapy for esophageal carcinoma. J Radiat Res. 2014:55(5):940-7.

20. Han X, Zhao YS, Fang Y, Qi Y, Li X, Jiao D, et al. Placement of transnasal drainage catheter and covered esophageal stent for the treatment of perforated esophageal carcinoma with mediastinal abscess. J Surg Oncol. 2016;114(6):725-30.

21. Huang J, Zhou Y, Wang C, Yuan W, Zhang Z. Chen B, et al, Logistic regression analysis of the risk factors of anastomotic fistula after radical resection of esophageal-cardiac cancer. Thorac Cancer. 2017:8(6):666-71.

22. Shariat SF, Capitanio U, Jeldres C, Karakiewicz PI. Can nomograms be superior to other prediction tools? BJU Int. 2009:103(4):492-5 discussion 5-7.

23. Ohtsu A, Boku N, Muro K, Chin K, Muto M, Yoshida S, et al. Definitive chemoradiotherapy for T4 and/or M1 lymph node squamous cell carcinoma of the esophagus. J Clin Oncol. 1999;17(9):2915-21.

24. Nakamura T, Hayashi K, Ota M, Eguchi R, Ide H, Takasaki K, et al. Salvage esophagectomy after definitive chemotherapy and radiotherapy for advanced esophageal cancer. Am J Surg. 2004;188(3):261-6.

25. Cacicedo J, Casquero F, Martinez-Indart L, Hoyo OD, Iturriaga AGD, Navarro $A$, et al. A prospective analysis of factors that influence weight loss in patients undergoing radiotherapy. Chin J Cancer. 2014;33(4):204-10.

26. Spencer ME, Jain A, Matteini A, Beamer BA, Wang NY, Leng SX, et al. Serum levels of the immune activation marker neopterin change with age and gender and are modified by race, BMI, and percentage of body fat. J. Gerontol. A. Biol. Sci. Med. Sci. 2010;65(8):858-65.

27. Hihara J, Hamai Y, Emi M, Aoki Y, Taomoto J, Miyata Y, et al. Esophageal bypass operation prior to definitive chemoradiotherapy in advanced esophageal cancer with tracheobronchial invasion. Ann Thorac Surg. 2014; 97(1):290-5

\section{Publisher's Note}

Springer Nature remains neutral with regard to jurisdictional claims in published maps and institutional affiliations.

\section{Ready to submit your research? Choose BMC and benefit from:}

- fast, convenient online submission

- thorough peer review by experienced researchers in your field

- rapid publication on acceptance

- support for research data, including large and complex data types

- gold Open Access which fosters wider collaboration and increased citations

- maximum visibility for your research: over $100 \mathrm{M}$ website views per year

At BMC, research is always in progress.

Learn more biomedcentral.com/submissions 